\title{
The Effect of Co Incorporation into ZnO Nanoparticles
}

\author{
Nadia Febiana Djaja, Dionisius Agung Montja, Rosari Saleh* \\ Departemen Fisika, FMIPA-Universitas Indonesia, Depok, Indonesia \\ Email: *rosari.saleh@ui.ac.id, ${ }^{*}$ rosari.saleh@gmail.com
}

Received December 29, 2012; revised February 3, 2013; accepted February 25, 2013

\begin{abstract}
Co-doped $\mathrm{ZnO}$ nanoparticles are synthesized by co-precipitation method. The incorporation of Co ions into $\mathrm{ZnO}$ wurzite structure with increasing Co concentrations was followed by X-ray diffraction. Sample structures were further studied by infrared spectra, from which a broad and strong absorption band in the range of $400-700 \mathrm{~cm}^{-1}$ and $-\mathrm{OH}$ stretching vibrational mode approximately $3400 \mathrm{~cm}^{-1}$ were observed. Ultraviolet-visible measurements showed a red shift of the absorption edge and four peaks at 468, 515, 577 and $629 \mathrm{~nm}$ in its reflectance spectra with increasing Co content. Magnetic measurements showed a ferromagnetic behavior for all samples. From the ESR spectra the presence of Co-metal clusters and Co-oxide precipitates are not observed and can be excluded as the origin of ferromagnetic in our samples. The ESR results are supported by UV-Vis measurements data.
\end{abstract}

Keywords: Transition-Metal-Doped ZnO Nanoparticles; Room-Temperature-Ferromagnetic; Co-Precipitation

\section{Introduction}

Transition metal (TM)-doped $\mathrm{ZnO}$ nanoparticles are promising candidates for a variety of practical applications due to their potential applications due to the charge and the spin of electrons that lead to a new magnetic, optical and transport properties of these materials. Numerous studies of these materials grown by several methods have exhibited room temperature ferromagnetic (RTFM) [1-4]. A number of studies have been reported to exhibit room temperature ferromagnetism in $\mathrm{V}-, \mathrm{Mn}-, \mathrm{Fe}-, \mathrm{Co}-, \mathrm{Ni}-$, and $\mathrm{Cu}$-doped $\mathrm{ZnO}$ [5-10]. However, the origin of the room temperature ferromagnetism is still a matter of controversy [11-14] and raised questions about the role of the dopants. According to theoretical prediction transition metal doping in metal oxide such as $\mathrm{ZnO}$ would lead to ferromagnetism behavior. However, in the experiments this ferromagnetism behavior is also inconsistent. It seems that ferromagnetism behavior is very sensitive to the preparation method. There is some evidence that the observed ferromagnetism in $\mathrm{TM}$-doped $\mathrm{ZnO}$ may arises from precipitation of secondary phase not from the replacement of $\mathrm{Zn}$ ion by $\mathrm{TM}$ ion in $\mathrm{ZnO}$ lattice $[15,16]$. On the other hand, there are results that exhibited the absence of secondary phase or magnetic clusters, supporting the intrinsic ferromagnetic origin. In addition, several groups [17-19] observed RTFM in undoped $\mathrm{ZnO}$, $\mathrm{TiO}_{2}$ and $\mathrm{HfO}_{2}$ which did not contain transition metal ions and proposed that the defects at $\mathrm{Zn}$ sites and oxygen

${ }^{*}$ Corresponding author. vacancies are responsible for the observed ferromagnetic behavior. Indeed, some authors [20-25] report that the presence of defects like oxygen vacancies play an important role in the indirect exchange mechanism. Recently, theoretical study suggested that oxygen vacancies can make a significant contribution to the ferromagnetism by forming bound magnetic polaron (BMP). From theoretical and experimental point of view the presence of ferromagnetism in transition metal doped- $\mathrm{ZnO}$ still continues to be an open topic.

In this work we report an investigation of structural, optical and magnetic properties of $\mathrm{ZnO}$ particles doped with Co. The co-precipitation method was used due to the method being cost effective, which requires low temperatures for processing and a high degree of solubility can be achieved [26]. The magnetic, structural, and electronic properties were investigated using a vibrating sample magnetometer (VSM), X-ray diffraction (XRD), energy dispersive X-ray (EDX) spectroscopy, Fouriertransform infrared spectroscopy, UV-Vis spectro-photometry and electron spin resonance (ESR).

\section{Experimental}

The starting materials, zinc sulfate heptahydrate $\left(\mathrm{ZnSO}_{4} \cdot 7 \mathrm{H}_{2} \mathrm{O}, 99 \%\right.$, Merck) and cobalt chloride hexahydrate $\left(\mathrm{CoCl}_{2} \cdot 6 \mathrm{H}_{2} \mathrm{O}, 99 \%\right.$, Aldrich) were used without further purification. Specific amounts of $\mathrm{ZnSO}_{4} \cdot 7 \mathrm{H}_{2} \mathrm{O}$ and $\mathrm{CoCl}_{2} \cdot 6 \mathrm{H}_{2} \mathrm{O}$ were dissolved in distilled water depending on the desired degree of Co-doping. For convenience, these solutions are designated as solution $\mathrm{A}$. 
Solution A was then placed in an ultrasonic cleaner operating at a $57 \mathrm{kHz}$ frequency for $2 \mathrm{~h}$. Simultaneously, 44 mmol $\mathrm{NaOH}$ was added to $440 \mathrm{~mL}$ of de-ionized water to generate solution B. After sonication solution A was subsequently stirred with a magnetic stirrer at room temperature and then solution B was added until the final $\mathrm{pH}$ of the solution reached 12 . The solution was further stirred for $0.5 \mathrm{~h}$ under constant magnetic stirring and then allowed to remain at room temperature for $18 \mathrm{~h}$. Subsequently, the solution was centrifuged and washed several times with ethanol and distilled water to remove residual and unwanted impurities. The final product was dried in a vacuum oven at $200^{\circ} \mathrm{C}$ for $1 \mathrm{~h}$ yielding Codoped $\mathrm{ZnO}$ powders.

The existence and composition of Co dopants were determined by energy-dispersive X-ray spectroscopy (EDX) LEO 420. To evaluate the phase purity of the samples, X-ray diffraction (XRD) measurements were performed using a Philips PW 1710 and monochromatic $\mathrm{Cu}-\mathrm{K} \alpha(\lambda=1.54060 \AA)$ radiation operated at $40 \mathrm{kV}$ and $20 \mathrm{~mA}$ in the range of $10^{\circ}$ to $80^{\circ}$. The instrumental broadening including the instrumental symmetry was calibrated using a $\mathrm{Si}$ powder standard sample. The X-ray diffraction patterns were analyzed by means of the MAUD program using the Rietveld whole profile fitting method to determine the crystal structure and lattice parameters.

Structural properties were further examined using Fourier transform infra red (FTIR) spectroscopy. FTIR spectra of the powder samples were recorded using a Shimadzu Fourier transform spectrometer. All spectra wereobtained using pressed pellets of the prepared samples in potassium bromide $(\mathrm{KBr})$ in the range of $400-4000$ $\mathrm{cm}^{-1}$ with a resolution of $4 \mathrm{~cm}^{-1}$.

To study the electronic interaction near the optical band gap resulting from the addition of dopant atoms diffuse reflectance UV-Vis measurements were performed using a Shimadzu UV-Vis spectrophotometer with an integrating sphere and a spectral reflectance standard in the wavelength range of $200-800 \mathrm{~nm}$.

Magnetic measurements were carried out at room temperature using an Oxford Type 1.2 $\mathrm{T}$ vibrating sample magnetometer (VSM). Powder samples were tightly packed in a clear plastic drinking straw. Magnetization data was recorded as a function of applied magnetic field from 0 to \pm 1 Tesla. The backgound signal from sample holder has been corrected for the data reported in this study.

To obtain information on oxidation state and site occupancy of the $\mathrm{Co}$ and $\mathrm{Mn}$ ions in the $\mathrm{ZnO}$ matrix electron spin resonance (ESR) was carried out using $\mathrm{X}$-band JEOL JES-RE1X at room temperature and an $\mathrm{X}$-band spectrometer equipped with $9.1 \mathrm{GHz}$ field modu- lation unit. The resonance was optimized for modulation amplitude, receiver gain, time constant and scan time. The amount of sample used in all measurements was kept constant. DPPH was used as the standard. The shape and area of the ESR spectra were analyzed using standard numerical methods.

\section{Results and Discussion}

EDX analysis confirmed the presence of doping elements in the samples. Table 1 provides representative EDX spectra for the Co-doped $\mathrm{ZnO}$ nanoparticles. Elemental analysis revealed that the samples contain target elements within the detection limit of EDX. Quantitative characterization of the $\mathrm{Co} / \mathrm{Zn}$ ratio was performed by calculating the area of the corresponding spectral $\mathrm{K}$ lines of EDX spectra. The amounts of $\mathrm{Co}$ in the $\mathrm{ZnO}$ particles were found to vary between 3 - 18 at $\%$. These results are an average of four values from different regions. Table 1 illustrates how the $\mathrm{Co}$ incorporation in $\mathrm{ZnO}$ nanoparticles varies as a function of the initial cations ratio used in the synthesis. It appears that the amounts of Co incorporated in the samples are slightly lower than the amounts of Co introduced in the synthesis.

XRD measurements were employed to investigate the structural properties and average crystallite size of the Co-doped $\mathrm{ZnO}$ samples, in addition to evaluate the phase purity. Representative XRD patterns shown in Figure 1 reveal the presence of the wurtzite $\mathrm{ZnO}$ phase and no other impurity phases even for samples doped with the highest Co concentrations of approximately 18 at $\%$. This indicates that the wurzite structure is not influenced by incorporation of Co. No secondary phases such as $\mathrm{CoO}$, $\mathrm{Co}_{2} \mathrm{O}_{3}$ or $\mathrm{ZnCo}_{2} \mathrm{O}_{4}$ were observed in the samples, as shown in Figure 1, suggesting that Co occupy the zinc sites in the Co-doped $\mathrm{ZnO}$ samples. In all XRD patterns, the (101) peak is dominant, and its intensity is higher than that of the other peaks indicated that the preferential growth of [101] orientation along c-axis for all samples. Compared to diffraction pattern of undoped $\mathrm{ZnO}$, the positions of diffraction peaks of Co-doped $\mathrm{ZnO}$ gradually change with doping, revealing interesting variations in $d$ values, lattice parameters $a$, and $c$ and lattice volume $V$.

The lattice constants were calculated from the Rietveld refinement of the diffraction pattern using the MAUD program and are summarized in Table 1. The results are comparable with those of undoped $\mathrm{ZnO}$ [27] and $\mathrm{CoO}$ [29].

A gradual decrease at the lattice parameter has been observed, dependent on the doping Co atoms in $\mathrm{ZnO}$ lattice. Although the change is very small, the variation of lattice parameters with the concentration of dopant gives an indication for the Co ions substituting in the 
Table 1. The Co/Zn ratio introduced in the synthesis and from EDX spectra, lattice parameters, lattice volume, ratio of lattice parameters, bond length $l$, average crystallite size $<D>$, and band gap of Co-doped $\mathrm{ZnO}$ nanoparticle.

\begin{tabular}{ccccccccccc}
\hline Sample & {$[\mathrm{Co} / \mathrm{Zn}]$} & $\mathrm{at} \%$ & $\mathrm{a}=\mathrm{b}(\AA)$ & $\mathrm{c}(\AA)$ & volume $\left(\AA^{3}\right)$ & $\mathrm{c} / \mathrm{a}$ & $l(\AA)$ & $<D>\mathrm{nm}$ & $\mathrm{Eg}(\mathrm{eV})$ \\
\hline $\mathrm{ZnO}$ & - & - & - & - & - & - & - & - & $3.52[27]$ \\
& 0.03 & 3 & 3.2548 & 5.2178 & 47.8704 & 1.6031 & 3.7425 & 27 & 3.34 \\
& 0.06 & 6 & 3.2534 & 5.2161 & 47.8136 & 1.6033 & 3.7413 & 22 & 3.31 \\
Co doped $\mathrm{ZnO}$ & 0.1 & 12 & 3.2490 & 5.2078 & 47.6085 & 1.6029 & 3.7353 & 20 & 3.28 \\
& 0.2 & 18 & 3.2467 & 5.2057 & 47.5219 & 1.6034 & 3.7339 & 18 & 3.26 \\
$\mathrm{CoO}$ & - & - & - & - & - & - & - & - & $2.3[28]$ \\
\hline
\end{tabular}

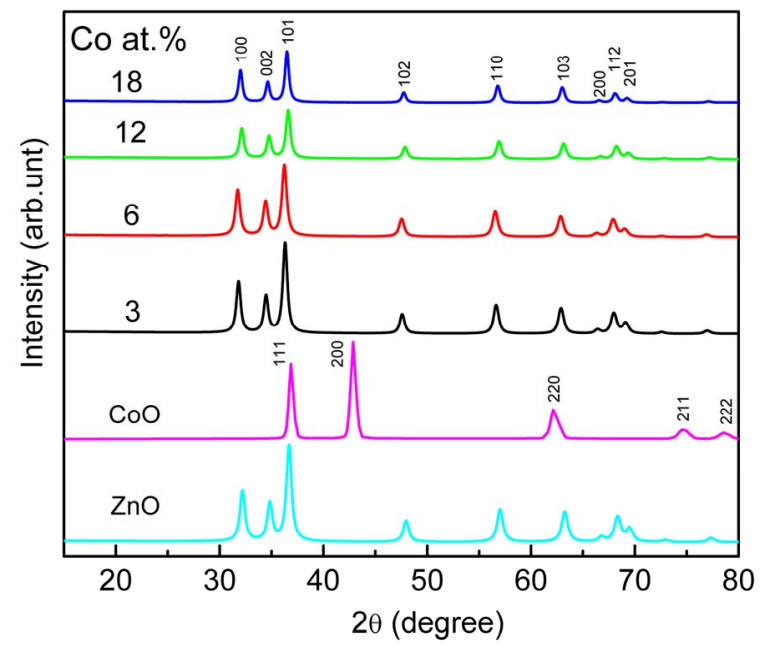

Figure 1. XRD patterns of undoped and Co-doped $\mathrm{ZnO}$ nanoparticles synthesized with different concentrations of Co.

$\mathrm{ZnO}$ lattice structure since the ionic radii of $\mathrm{Co}^{2+}(0.58 \AA)$ are less than that of $\mathrm{Zn}^{2+}$. The ratio of lattice parameters (c/a) as a function of dopant concentration is also shownon Table 1. The values have a good correlation with the standard value (1.60) and indicated that Co ions are able to substitute the $\mathrm{Zn}$ ions in the $\mathrm{ZnO}$ lattice without influence the overall crystal structure. It is also expected that with increasing dopant concentrations the $\mathrm{Zn}-\mathrm{O}$ bond length $l$ could be changed due to the change in lattice parameters. The bond length as a function of dopant concentrations is tabulated in Table 1. It is observed that the substitutional doping does not change significantly the $\mathrm{Zn}-\mathrm{O}$ bond length $l$ and the mean values are $\approx 3.74 \AA$. It is known that the breadth of the XRD peak can be linked to the average crystallite size, microstrain and defects or dislocations.

The average crystallite size using XRD measurements is not generally the same as the particle size due to powder aggregates. The average crystallite size as related to the line broadening can be calculated using Scherrer's equation, as given in Equation (2):

$$
\langle D\rangle=\frac{K \lambda}{(\beta \cos \theta)}
$$

where $\langle D\rangle=$ volume weighted crystallite size, $K=$ shape factor (close to unity in our work, it was set to 0.9 ), $\lambda=$ wavelength of $\mathrm{Cu}-\mathrm{K} \alpha, \beta_{\mathrm{hkl}}=\left[\beta_{\mathrm{hkl} \text { measured }}^{2}-\beta_{\text {instrumental }}^{2}\right]^{1 / 2}$ $=$ instrumental corrected integral breadth of the reflection located at $2 \theta$, and $\theta=$ angle of reflection. The average crystallite size for the Co-doped $\mathrm{ZnO}$ calculated using Scherrer's equation is presented in Table 1.

The formation of $\mathrm{ZnO}$ wurtzite structures in the Codoped $\mathrm{ZnO}$ samples was further supported by FTIR measurements. Similar spectra were obtained for the undoped $\mathrm{ZnO}$ as well as the Co-doped $\mathrm{ZnO}$ samples (Figure 2). Analysis of the FTIR spectra was done based on the results of nanoparticles published in the literature [30-32]. For all doped and undoped $\mathrm{ZnO}$ samples the absorption peaks in the range of $400-700 \mathrm{~cm}^{-1}$ could be attributed to the $\mathrm{ZnO}$ stretching modes [33]. In our FTIR spectra the main peaks observed were: 1) absorption peaks in the range of $1100-1600 \mathrm{~cm}^{-1}$ corresponding to the $\mathrm{Zn}-\mathrm{OH}$ bending mode [34], and this band could be normally reduced by calcinations process at higher temperature $[35,36]$ and to $\mathrm{C}-\mathrm{OH}$ plane bending and $\mathrm{C}-\mathrm{OH}$ out-of-plane bending [37]; 2) a broad band in the 2900 $3700 \mathrm{~cm}^{-1}$ region which can be explained as overlapping $\mathrm{O}-\mathrm{H}$ stretching modes and $\mathrm{C}-\mathrm{H}$ stretching modes. $\mathrm{C}-\mathrm{H}$ local vibrational modes between 2800 and $3100 \mathrm{~cm}^{-1}$ have been observed in a number of semi-conductors [3840]. In these materials, the local vibrational modes are assigned to the symmetric and antisymmetric $\mathrm{C}-\mathrm{H}$ stretching modes.

To study the electronic interactions near the optical band gap region due to the presence of dopants diffusereflectance measurements were performed on the samples in the UV-Vis region at room temperature. All spectra were obtained in the range of $200-800 \mathrm{~nm}$. Figure 3 shows the diffuse-reflectance spectra, R, as a function of wavelength for samples shown in Figure 1. The spectra of Co-doped $\mathrm{ZnO}$ particles show peaks at 


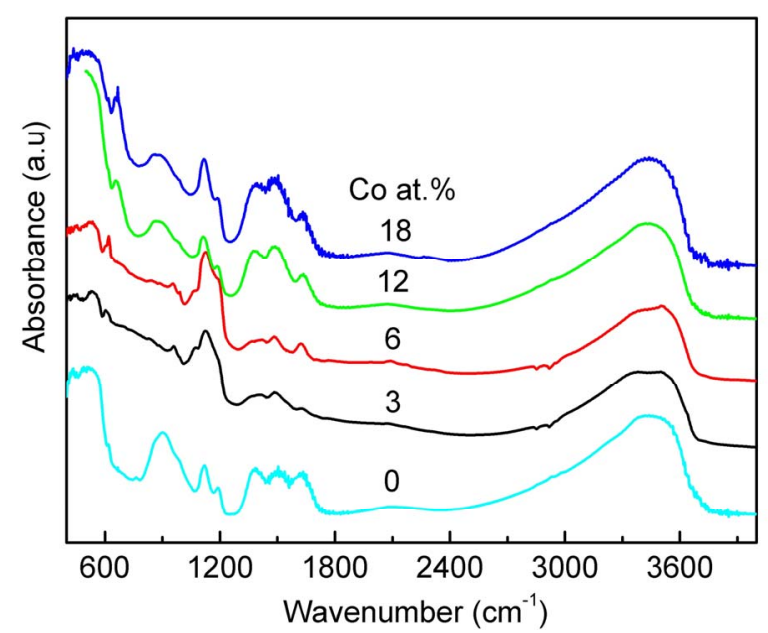

Figure 2. FTIR spectra of the Co-doped $\mathrm{ZnO}$ nanoparticles at various doping concentrations. The spectra are shifted vertically for clarity.

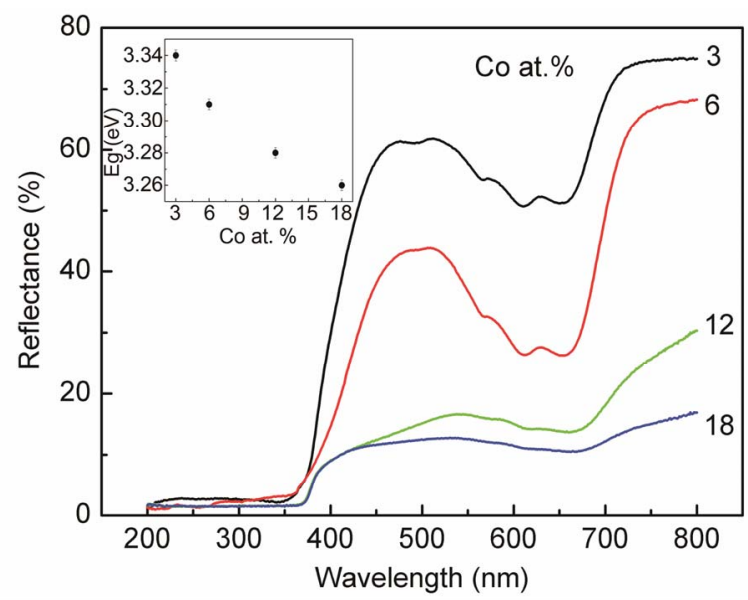

Figure 3. Diffuse-reflectance spectra of the Co-doped $\mathrm{ZnO}$ nanoparticles synthesized at various doping concentrations. The inset shows the correlated optical band gap of the Codoped $\mathrm{ZnO}$ nanoparticles as a function of the doping concentrations.

$468,515,577$ and $629 \mathrm{~nm}$. It is reported, that these peaks are only possible in a $\mathrm{Co}^{2+}$ ion with $3 \mathrm{~d}^{7}$ high-spin configuration in a tetrahedral crystal field [3,41-49]. They were ascribed to ${ }^{4} \mathrm{~A}_{2}(\mathrm{~F}) \rightarrow{ }^{2} \mathrm{~A}_{1}(\mathrm{G}),{ }^{4} \mathrm{~A}_{2}(\mathrm{~F}) \rightarrow{ }^{4} \mathrm{~T}_{1}$ $(\mathrm{P})$, and ${ }^{4} \mathrm{~A}_{2}(\mathrm{~F}) \rightarrow{ }^{2} \mathrm{~T}_{1}(\mathrm{G})$ transitions in high spin states $(\mathrm{S}=3 / 2)$. The appearance of these transitions suggested that $\mathrm{Co}^{2+}$ ions substituted the $\mathrm{Zn}^{2+}$ in $\mathrm{ZnO}$ lattice. It may be noted that the peaks smeared out and the intensity of the reflection spectra decreased at Co concentration higher than 6 at $\%$, indicated that additional Co ion incorporated into $\mathrm{ZnO}$ occupied sites with a different local crystal field [3].

The bandgap energy of the doped Co-doped $\mathrm{ZnO}$ samples was calculated from the diffuse-reflectance spectra by plotting the square of the Kubelka-Munk function $\mathrm{F}(\mathrm{R})^{2}$ vs. the energy in electron volts. The linear part of the curve was extrapolated to $\mathrm{F}(\mathrm{R})^{2}=0$ to calculate the direct band gap energy. The inset of Figure 3 shows the bandgap as a function of the doping concentrations.

The absorption edge shifts to lower energies/longer wavelength. A similar shift in the absorption edge and band gap energy upon transition-metal (TM) doping was reported in $\mathrm{Co}-, \mathrm{Ni}-$, and $\mathrm{Cr}$-doped $\mathrm{ZnO}$ nanoparticles [50-52] as well as other TM-doped semiconductor nanoparticles systems [53-55]. In addition to the reduction in the band gap energy, a decrease in the diffuse reflectance was also observed with increasing dopant concentration. The redshift of the band gap energy with incorporation of dopant into $\mathrm{ZnO}$ lattice was interpreted as mainly due to the $s p-d$ exchange interactions between the band electrons and the localized $d$ electrons of the dopant ions substituting $\mathrm{Zn}$ ions [32]. It is believed that the $s-d$ and $p-d$ exchange interactions lead to a negative and a positive correction to the conduction band as well as the valence band edges resulting in a band gap narrowing $[32,45]$.

Information about the magnetic properties of Codoped $\mathrm{ZnO}$, was obtained by room temperature VSM measurements. The results are displayed in Figure 4. Plotted is the magnetization as a function of magnetic field for different contents of dopant. It is interesting to note that all the samples of the present investigation show ferromagnetic behavior. As is seen in Figure 4 the Co-doped sample has a well-defined hysteresis at room temperature with coercive field $\left(\mathrm{H}_{\mathrm{C}}\right)$ and the remnant magnetization $\left(\mathrm{M}_{\mathrm{R}}\right)$ increased with increasing doping concentrations. The coercive field $\left(\mathrm{H}_{\mathrm{C}}\right)$ and the remnant magnetization $\left(\mathrm{M}_{\mathrm{R}}\right)$ are found to decrease. The values of $M_{R}$ and $H_{C}$ are summarized in Table 2. Accordingly, $M_{R}$

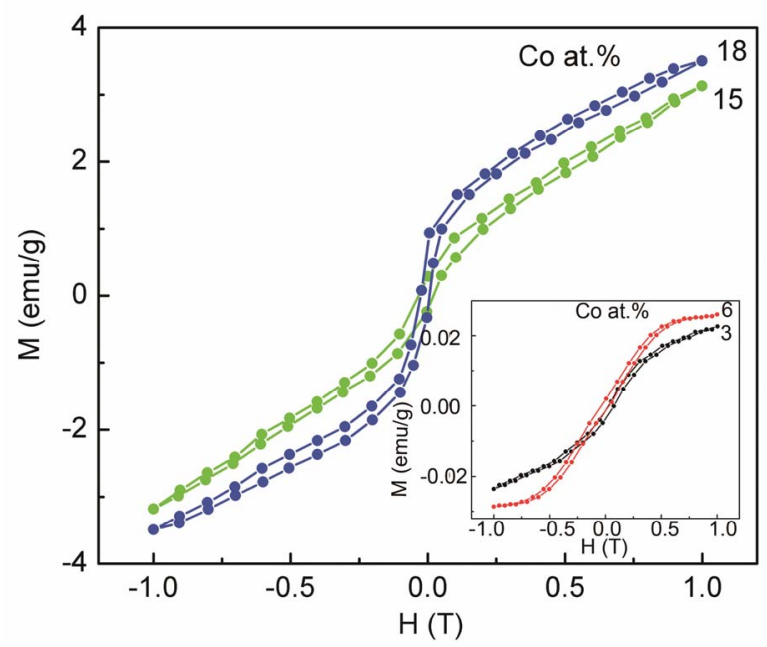

Figure 4. Room temperature M-H curves for Co-doped ZnO nanoparticles synthesized with various doping concentrations. 
Table 2. The g value, linewidth $\left(\Delta \mathrm{H}_{\mathrm{pp}}\right)$, peak area, coercive field $\left(\mathrm{H}_{\mathrm{C}}\right)$ and the remnant magnetization $\left(\mathrm{M}_{\mathrm{R}}\right)$ of $\mathrm{Co-doped} \mathrm{ZnO}$ nanoparticle.

\begin{tabular}{|c|c|c|c|c|c|c|}
\hline Sample & at $\%$ & $\mathrm{~g}$ value & $\Delta \mathrm{H}_{\mathrm{PP}}$ & Area $\left(\times 10^{6}\right)$ & $\mathrm{M}_{\mathrm{R}}(\mathrm{emu} / \mathrm{g})$ & $\mathrm{H}_{\mathrm{C}}(\mathrm{Oe})$ \\
\hline \multirow{4}{*}{ Co doped $\mathrm{ZnO}$} & 3 & 2.2005 & 328 & 319 & 0.002 & 530 \\
\hline & 6 & 2.2558 & 352 & 675 & 0.001 & 350 \\
\hline & 12 & 2.2902 & 392 & 1160 & 0.284 & 275 \\
\hline & 18 & 2.3298 & 488 & 2670 & 0.664 & 235 \\
\hline
\end{tabular}

value for all concentrations lies in the range of 0.002 $0.664 \mathrm{emu} / \mathrm{g}$. The results obtained from VSM measurements were further confirmed by room temperature ferromagnetic resonance signals observed in the ESR measurements.

In Figure 5 the ESR spectra of Co-doped $\mathrm{ZnO}$ samples with different Co concentration in the range of $3-18$ at $\%$ are shown. It is known that the $\mathrm{Co}^{2+}$ ion has $3 \mathrm{~d}^{7}$ and the electronic ground state is $\mathrm{S}_{7 / 2}$. The only natural isotope is ${ }^{59} \mathrm{Co}$ and the ESR spectrum is expected to show eight fine transitions. However, the ESR spectra of Codoped $\mathrm{ZnO}$ samples investigated here showed only a broad signal without splitting into additional peaks.

The broad signal was attributed to ferromagnetic resonance, which arises from long range exchange interaction and from transitions within the ground sate of the ferromagnetic domain [3,55-57]. For all Co-doped samples the shape of ESR spectrum can be fitted with Gaussian in the entire range of magnetic field. The peak position and the linewidth $\left(\Delta \mathrm{H}_{\mathrm{pp}}\right)$ vary strongly with dopant concentrations. The peak position shifted to the lower magnetic field while the $\Delta \mathrm{H}_{\mathrm{pp}}$ shows monotonous increase with increasing dopant concentration as expected for a ferromagnetic material [58-60]. It is believed that the observed broadening of the signal is due to the presence of a non-homogeneous local magnetic field, which modifies the resonance field as well as the line shape of the signal [4]. The corresponding g-values increased from 2.2005 to 2.3298 as Co concentration increased from 3 to 18 at\% (Table 2).

The mechanism responsible for the observed ferromagnetism at room temperature in transition metal-doped $\mathrm{ZnO}$ is also not clear and has been debated over the years. Nevertheless a few researchers have claimed to observe ferromagnetic behavior arising only from a secondary phase and not from the intrinsic property of the material itself. The results of the XRD and EDX measurements in our Co-doped samples demonstrate that the dopant ion was incorporated into the wurtzite lattice at $\mathrm{Zn}$ sites forming a solid solution instead of precipitates. However, a secondary phase might exist in the sample even though it was not detected in our XRD spectra. Thus, it is useful to consider all possible ferromagnetic impurity phases



Figure 5. Experimental ESR spectra of the Co-doped $\mathrm{ZnO}$ nanoparticles prepared at various Co concentrations.

that might be present in Co-doped $\mathrm{ZnO}$. In Co-doped $\mathrm{ZnO}$ samples the possible secondary phase is due to Cometal clusters or Co-oxide precipitates. The possible Co-based oxides, such as $\mathrm{CoO}$ and $\mathrm{Co}_{2} \mathrm{O}_{3}$ are antiferromagnetic with $\mathrm{T}_{\mathrm{N}}$ values of 293 and $30 \mathrm{~K}$, respectively [61-63].

Moreover, from the ESR spectra the presence of Cometal clusters and Co-oxide precipitates are not observed and can be excluded as the origin of RTFM in our Co-doped samples. The ESR results are supported by UV-Vis measurements data which show the characteristic transition of $\mathrm{Co}^{2+}$ ions. Therefore, according to the characterization methods applied in the present study, the ferromagnetism behavior observed in our Co-doped samples studied here does not seem to be related with the presence of any secondary phases. Therefore ferromagnetism is expected to arise from the intrinsic exchange interaction of ferromagnetic in our transition metal doped $\mathrm{ZnO}$ samples.

There are several mechanisms proposed in the literature, such as ferromagnetism induced by structural changes [64-66], Ruderman-Kittel-Kasuya-Yosida (RKKY) interaction, super-exchange, double exchange between the $d$ states of transition metal ions, free-carriedmediated exchange and $s p$ - $d$ exchange mechanism etc. $[67,68]$. However, all of these proposed theories cannot well accord with this present experimental results. In a 
recent paper, Coey et al. [20] proposed a ferromagnetic exchange mechanism involving oxygen vacancies $\left(\mathrm{V}_{\mathrm{O}}\right)$, which form F-centers with trapped electron, for the observed ferromagnetism in transition metal-doped oxide semiconductors. Overlap of the F-center electron orbitals with the $d$ orbitals of the neighboring transition metal spins (TMs) to form $\mathrm{TMs}-\mathrm{V}_{\mathrm{O}}-\mathrm{TMs}$ groups is crucial for the proposed ferromagnetism coupling [20]. From the discussion above, the ferromagnetic exchange mechanism involving oxygen vacancies model is an appropriate explanation for the observed RTFM behavior in our Co-doped samples. It would indicate that the oxygen vacancies are present in our transition metal doped $\mathrm{ZnO}$.

\section{Summary}

In summary, Co-doped $\mathrm{ZnO}$ particles have been synthesized using the co-precipitation method and we have characterized their structural, optical and magnetic properties as a function of doping concentrations. No secondary phase was observed within the sensitifity of X-ray diffraction method. The optical band gap was found to decrease with increasing doping concentrations, indicating a clear red shift. All samples were found to exhibit room-temperature ferromagnetism. The specific magnetization-values were found to increase with increasing Co concentrations. From the ESR spectra in our dopant range, we obtained a broad line with g-value range from 2.23 to 2.17 attributed to ferromagnetic resonance arising from $\mathrm{Co}^{2+}$ ions. This result is consistent with the result obtained from VSM and UV-Vis measurements.

\section{REFERENCES}

[1] P. Sharma, A. Gupta, K. V. Rao, F. J. Owens, R. Sharma, R. Ahuja, J. M. Osorio and B. Johansson, "Ferromagnetism above Room Temperature in Bulk and Transparent Thin Films of Mn-Doped ZnO," Nature Matter, Vol. 2, No. 23, 2003, pp. 673-677. doi:10.1038/nmat984

[2] H.-W. Zhang, Z.-R. Wei, Z.-Q. Li and G.-Y. Dong, "Room-Temperature Ferromagnetism in Fe-Doped, Feand $\mathrm{Cu}$-Codoped $\mathrm{ZnO}$ Diluted Magnetic Semiconductor," Materials Letters, Vol. 61, No. 17, 2007, pp. 3605-3607. doi:10.1016/j.matlet.2006.11.139

[3] J. Hays, K. M. Reddy, N. Y. Graces, M. H. Engelhard, V. Shutthanandan, M. Luo, C. Xu, N. C. Giles, C. Wang, S. Thevuthasan and A. Punnoose, "Effect of Co Doping on the Structural, Optical and Magnetic Properties of $\mathrm{ZnO}$ Nanoparticles," Journal of Physics: Condensed Matter, Vol. 19, No. 26, 2007, Article ID: 266203. doi:10.1088/0953-8984/19/26/266203

[4] K. Srinivas, S. M. Rao and P. V. Reddy, "Preparation and Properties of $\mathrm{Zn}_{0.9} \mathrm{Ni}_{0.1} \mathrm{O}$ Diluted Magnetic Semiconductor Nanoparticles," Journal of Nanoparticle Research, Vol. 13, No. 2, 2011, pp. 817-837. doi:10.1007/s11051-010-0084-2

[5] N. Tahir, S. T. Hussain, M. Usman, S. K. Hasanain and A.
Mumtaz, "Effect of Vanadium Doping on Structural, Magnetic, and Optical Properties of $\mathrm{ZnO}$ Nanoparticles," Applied Surface Science, Vol. 255, No. 20, 2009, pp. 85068510. doi:10.1016/j.apsusc.2009.06.003

[6] J. L. Costa-Krämer, F. Briones, J. F. Fernández, A. C. Caballero, M. Villegas, M. Díaz, M. A. García and A. Hernando, "Nanostructure and Magnetic Properties of the MnZnO System, a Room Temperature Magnetic Semiconductor?" Nanotechnology, Vol. 16, No. 2, 2005, p. 214. doi:10.1088/0957-4484/16/2/006

[7] D. Karmakar, S. K. Mandal, R. M. Kadam, P. L. Paulose, A. K. Rajarajan, T. K. Nath, A. K. Das, I. Dasgupta and G. P. Das, "Ferromagnetism in Fe-Doped ZnO Nanocrystals: Experiment and Theory," Physical Review B, Vol. 75, No. 14, 2007, Article ID: 144404. doi:10.1103/PhysRevB.75.144404

[8] Y. K. Lakshmi, K. Srinivas, B. Sreedhar, M. M. Raja, M. Vithal and P. V. Reddy, "Structural, Optical, and Magnetic Properties of Nanocrystalline $\mathrm{Zn}_{0.9} \mathrm{Co}_{0.1} \mathrm{O}$-Based Diluted Magnetic Semiconductors," Materials Chemistry and Physics, Vol. 113, No. 2-3, 2009, pp. 749-755. doi:10.1016/j.matchemphys.2008.08.021

[9] J. J. Lu, T. C. Lin, S. Y. Tsai, T. S. Mo and K. J. Gan, "Structural, Magnetic and Transport Properties of NiDoped ZnO Films," Journal of Magnetism and Magnetic Materials, Vol. 323, No. 6, 2011, pp. 829-832. doi:10.1016/j.jmmm.2010.11.025

[10] D. B. Buchholz, R. P. H. Chang, J.-Y. Song and J. B. Ketterson, "Room-Temperature Ferromagnetism in $\mathrm{Cu}$ Doped ZnO Thin Films," Applied Physics Letters, Vol. 87, No. 8, 2005, Article ID: 082504. doi:10.1063/1.2032588

[11] J. H. Li, D. Z. Shen, J. Y. Zhang, D. X. Zhao, B. S. Li, Y. M. Lu, Y. C. Liu and X. W. Fan, "Magnetism Origin of Mn-Doped ZnO Nanoclusters," Journal of Magnetism and Magnetic Materials, Vol. 302, No. 1, 2006, pp. 118121. doi:10.1016/j.jmmm.2005.08.025

[12] S. Banerjee, K. Rajendran, N. Gayathri, M. Sardar. S. Senthilkumar and V. Sengodan, "Change the Room Temperature Magnetic Property of $\mathrm{ZnO}$ upon Mn Doping," Journal of Applied Physics, Vol. 104, No. 4, 2008, Article ID: 043913. doi:10.1063/1.2969945

[13] K. Sato and H. Katayama-Yoshida, "Ferromagnetism in a Transition Metal Atom Doped ZnO," Physica E, Vol. 10, No. 1-3, 2001, pp. 251-255. doi:10.1016/S1386-9477(01)00093-5

[14] T. Dietl, H. Ohno, F. Matsukura, J. Cibert and D. Ferrand, "Zener Model Description of Ferromagnetism in ZincBlende Magnetic Semiconductors," Science, Vol. 287, No. 5455, 2000, pp. 1019-1022. doi:10.1126/science.287.5455.1019

[15] J. H. Park, M. G. Kim, H. M. Jang, S. Ryu and Y. M. Kim, "Co-Metal Clustering as the Origin of Ferromagnetism in Co-Doped ZnO Thin Films," Applied Physics Letters, Vol. 84, No. 8, 2004, pp. 1338-1340. doi:10.1063/1.1650915

[16] S. A. Chambers, T. Droubay, C. M. Wang, A. S. Lea, R. F. C. Farrow, L. Folks, V. Deline and S. Anders, "Clusters and Magnetism in Epitaxial Co-Doped $\mathrm{TiO}_{2}$ Anatase," Applied Physics Letters, Vol. 82, No. 8, 2003, p. 
1257. doi:10.1063/1.1556173

[17] M. Venkatesan, C. B. Fitzgerald and J. M. D. Coey, "Thin Films: Unexpected Magnetism in a Dielectric Oxide," Nature, Vol. 430, No. 7000, 2004, p. 630. doi:10.1038/430630a

[18] A. Sundaresan, R. Bhargavi, N. Rangarajan, U. Siddesh and C. N. R. Rao, "Ferromagnetism as a Universal Feature of the Otherwise Nonmagnetic Oxides," Physical Review B, Vol. 74, No. 16, 2006, Article ID: 161306. doi:10.1103/PhysRevB.74.161306

[19] N. H. Hong, J. Sakai and V. Brize, "Observation of Ferromagnetism at Room Temperature in ZnO Thin Films," Journal of Physics: Condensed Matter, Vol. 19, No. 3, 2007, Article ID: 036219. doi:10.1088/0953-8984/19/3/036219

[20] J. M. Coey, M. Venkatesan and C. B. Fitzgerald, "Donor Impurity Band Exchange in Dilute Ferromagnetic Oxides," Nature Matter, Vol. 4, No. 4, 2005, pp. 173-179. doi:10.1038/nmat1310

[21] L. B. Duan, G. H. Rao, J. Yu, Y. C. Wang, W. G. Chu and L. N. Zhang, "Structural and Magnetic Properties of $\mathrm{Zn}_{1-\mathrm{X}} \mathrm{Mn}_{\mathrm{X}} \mathrm{O}(0 \leq \mathrm{X} \leq 0.40)$ Nanoparticles," Journal of Applied Physics, Vol. 102, No. 10, 2007, Article ID: 103907. doi:10.1063/1.2815647

[22] M. El-Hilo and A. A. Dakhel, "Structural and Magnetic Properties of Mn-Doped ZnO Powders," Journal of Magnetism and Magnetic Materials, Vol. 323, No. 16, 2011, pp. 2202-2205. doi:10.1016/j.jmmm.2011.03.031

[23] S. J. Han, J. W. Song, C. H. Yang, S. H. Park, Y. H. Jeong and K. W. Rhie, "A Key to Room-Temperature Ferromagnetism in Fe Doped $\mathrm{ZnO}: \mathrm{Cu}$," Applied Physics Letters, Vol. 81, No. 22, 2002, p. 4212. doi:10.1063/1.1525885

[24] X. X. Liu, F. T. Lin, L. L. Sun, W. J. Cheng, X. M. Ma and W. Z. Shi, "Doping Concentration Dependence of Room-Temperature Ferromagnetism for Ni-Doped $\mathrm{ZnO}$ Thin Films Prepared by Pulsed-Laser Deposition," $A p$ plied Physics Letters, Vol. 88, No. 6, 2006, Article ID: 062508. doi:10.1063/1.2170420

[25] M. El-Hilo, A. A. Dakhel and A. Y. Ali-Mohamed, "Room Temperature Ferromagnetism in Nanocrystalline Ni-Doped $\mathrm{ZnO}$ Synthesized by Co-Precipitation," Journal of Magnetism and Magnetic Materials, Vol. 321, No. 24, 2009, pp. 2279-2283. doi:10.1016/j.jmmm.2009.01.040

[26] O. D. Jayakumar, H. G. Salunke, R. M. Kadam, M. Mohapatra, G. Yaswant and S. K. Kulshreshtha, "Magnetism in Mn-Doped ZnO Nanoparticles Prepared by A Co-Precipitation Method," Nanotechnology, Vol. 17, No. 5, 2006, pp. 1278-1285. doi:10.1088/0957-4484/17/5/020

[27] S. P. Prakoso and R. Saleh, "Hydrogen Incorporation in Undoped ZnO Nanoparticles," World Journal of Condensed Matter Physics, Vol. 1, No. 4, 2011, pp. 130-136. doi:10.4236/wjcmp.2011.14019

[28] M. A. White, S. T. Ochsenbein and D. R. Gamelin, "Colloidal Nanocrystals of Wurtzite $\mathrm{Zn}_{1-\mathrm{X}} \mathrm{Co}_{\mathrm{X}} \mathrm{O}(0 \leq \mathrm{x} \leq 1)$ : Models of Spinodal Decomposition in an Oxide Diluted Magnetic Semiconductor," Chemistry of Materials, Vol. 20, No. 22, 2008, pp. 7107-7116. doi: $10.1021 / \mathrm{cm} 802280 \mathrm{~g}$

[29] Y. Yu, G. B. Ji, J. M. Cao, J. S. Liu and M. B. Zheng, "Facile Synthesis, Characterization and Electrochemical Properties of Cuspate Deltoid CoO Crystallites," Journal of Alloys and Compounds, Vol. 471, No. 1-2, 2009, pp. 268-271. doi:10.1016/j.jallcom.2008.03.074

[30] C. J. Cong, L. Liao, Q. Y. Liu, J. C. Li and K. L. Zhang, "Effects of Temperature on the Ferromagnetism of MnDoped ZnO Nanoparticles and Mn-Related Raman Vibration," Nanotechnology, Vol. 17, No. 5, 2006, p. 1520. doi:10.1088/0957-4484/17/5/059

[31] S. Senthilkumaar, K. Rajendra, S. Banerjee, T. K. Chini and V. Sengodan, "Influence of Mn Doping on the Microstructure and Optical Property of ZnO," Material Scince Semiconductor Processing, Vol. 11, No. 1, 2008, pp. 6-12. doi:10.1016/j.mssp.2008.04.005

[32] S. Maensiri, P. Laokul and S. Phokha, "A Simple Synthesis and Magnetic Behavior of Nanocrystalline $\mathrm{Zn}_{0.9} \mathrm{Co}_{0.1} \mathrm{O}$ Powders by Using $\mathrm{Zn}$ and Co Acetates and Polyvinyl Pyrrolidone as Precursors," Journal of Magnetism and Magnetic Materials, Vol. 305, No. 2, 2006, pp. 381-387. doi:10.1016/i.jmmm.2006.01.115

[33] A. Hernández, L. Maya, E. Sánchez-Mora and E. M. Sánchez, "Sol-Gel Synthesis, Characterization and Photocatalytic Activity of Mixed Oxide $\mathrm{ZnO}-\mathrm{Fe}_{2} \mathrm{O}_{3}$," Journal of Sol-Gel Science and Technology, Vol. 42, No. 1, 2007, pp. 71-78. doi:10.1007/s10971-006-1521-7

[34] J. Das, I. R. Evans and D. Khushalani, "Zinc Glycolate: A Precursor to ZnO," Inorganic Chemistry, Vol. 48, No. 8, 2009, pp. 3508-3510. doi:10.1021/ic900067w

[35] S. Maensiri, P. Laokul and J. Klinkaewnarong, "A Simple Synthesis and Room-Temperature Magnetic Behavior of Co-Doped Anatase $\mathrm{TiO}_{2}$ Nanoparticles," Journal of Magnetism and Magnetic Materials, Vol. 302, No. 2, 2006, pp. 448-453. doi:10.1016/j.jmmm.2005.10.005

[36] Y. F. Chen, C. Y. Lee, M. Y. Yeng and H. T. Chiu, "The Effect of Calcination Temperature on the Crystallinity of $\mathrm{TiO}_{2}$ Nanopowders," Journal of Crystal Growth, Vol. 247, No. 3-4, 2003, pp. 363-370. doi:10.1016/S0022-0248(02)01938-3

[37] S. P. Prakoso and R. Saleh, "Synthesis and Spectroscopic Characterization of Undoped Nanocrytalline ZnO Particles Prepared by Co-Precipitation," Materials Sciences and Applications, Vol. 3, No. 8, 2012, pp. 530-537. doi: $10.4236 / \mathrm{msa} .2012 .38075$

[38] R. Saleh, L. Munisa and W. Beyer, "Infrared Absorption in a-SiC:H Alloy Prepared by d.c. Sputtering," Thin Solid Films, Vol. 426, No. 1-2, 2003, pp. 117-123. doi:10.1016/S0040-6090(03)00003-8

[39] M. O. Manasreh, J. M. Baranowski, K. Pakula, X. X. Jiang and J. Lin, "Localized Vibrational Modes of Carbon-Hydrogen Complexes in GaN," Applied Physics Letter, Vol. 75, No. 5, 1999, pp. 659-661. doi: $10.1063 / 1.124473$

[40] D. M. Joseph, R. Balagopal, R. F. Hicks, L. P. Sadwick and K. L. Wang, "Observation of Carbon Incorporation during Gallium Arsenide Growth by Molecular Beam Epitaxy," Applied Physics Letter, Vol. 53, No. 22, 1988, 


\section{p. 2203. doi:10.1063/1.100281}

[41] M. Tortosa, M. Mollar, B. Mari and F. Lloret, "Optical and Magnetic Properties of $\mathrm{ZnCoO}$ Thin Films Synthesized by Electrodeposition," Journal of Applied Physics, Vol. 104, No. 3, 2008, Article ID: 033901. doi:10.1063/1.2952548

[42] A. Dinia, J. P. Ayoub, G. Schmerber, E. Beaurepaire, D. Muller and J. J. Grob, "Effect of Ion Irradiation on the Structural and the Magnetic Properties of $\mathrm{Zn}_{0.75} \mathrm{Co}_{0.25} \mathrm{O}$ Magnetic Semiconductors," Physics Letters A, Vol. 333, No. 1-2, 2004, pp. 152-156. doi:10.1016/j.physleta.2004.10.027

[43] G. L. Liu, Q. Cao, J. X. Deng, P. F. Xing, Y. F. Tian, Y. X. Chen, S. S. Yan and L. M. Mei, "High TC Ferromagnetism of $\mathrm{Zn}_{1-\mathrm{x}} \mathrm{Co}_{\mathrm{x}} \mathrm{O}$ Diluted Magnetic Semiconductors Grown by Oxygen Plasma-Assisted Molecular Beam Epitaxy," Applied Physics Letters, Vol. 90, No. 6, 2007, Article ID: 052504. doi:10.1063/1.2437111

[44] S. Ramachandran, A. Tiwari and J. Narayan, " $\mathrm{Zn}_{0.9} \mathrm{Co}_{0.1} \mathrm{O}$ Based Diluted Magnetic Semiconducting Thin Films," Applied Physics Letters, Vol. 84, 2004, p. 5255. doi:10.1063/1.1764936

[45] P. Koidl, "Optical Absorption of $\mathrm{Co}^{2+}$ in $\mathrm{ZnO}$," Physical Review B, Vol. 15, No. 5, 1977, pp. 2493-2499. doi:10.1103/PhysRevB.15.2493

[46] S. D. Kshirsagar, D. Inamdar, I. K. Gopalakrishnan, S. K. Kulshreshtha and S. Mahamuni, "Formation of RoomTemperature Ferromagnetic $\mathrm{Zn}_{1-\mathrm{X}} \mathrm{Co}_{\mathrm{X}} \mathrm{O}$ Nanocrystals," Solid State Communications, Vol. 143, No. 10, 2007, pp. 457-460. doi:10.1016/j.ssc.2007.06.025

[47] Y. Z. Yoo, T. Fukumura, Z. Jin, K. Hasegawa, M. Kawasaki, P. Ahmet, T. Chikyow and H. Koinuma, "ZnO-CoO Solid Solution Thin Films," Journal of Applied Physics, Vol. 90, No. 8, 2001, p. 4246. doi: $10.1063 / 1.1402142$

[48] C. J. Cong, J. H. Hong and K. L. Zhang, "Effect of Atmosphere on the Magnetic Properties of the Co-Doped ZnO Magnetic Semiconductors," Materials Chemistry and Physics, Vol. 113, No. 1, 2009, pp. 435-440. doi:10.1016/j.matchemphys.2008.06.062

[49] S. Yang, B. Y. Man, M. Liu, C. S. Chen, X. G. Gao, C. C. Wang and B. Hu, "Structural, Optical and Magnetic Properties of $\mathrm{Zn}_{1-\mathrm{X}} \mathrm{Co}_{\mathrm{X}} \mathrm{O}$ Dilute Magnetic Semiconductors Thin Films by Pulsed Laser Deposition," Physica B, Vol. 405, No. 18, 2010, pp. 4027-4031. doi:10.1016/j.physb.2010.06.050

[50] H. Yang and S. Nie, "Preparation and Characterization of Co-Doped ZnO Nanomaterials," Materials Chemistry and Physics, Vol. 114, No. 1, 2009, pp. 279-282. doi:10.1016/j.matchemphys.2008.09.017

[51] R. Elilaressi and G. Chandrasekaran, "Structural, Optical, and Magnetic Properties of Nanoparticles of $\mathrm{ZnO}: \mathrm{Ni}-$ DMS Prepared by Sol-Gel Method," Materials Chemistry Physics, Vol. 123, No. 2-3, 2010, pp. 450-455. doi:10.1016/j.matchemphys.2010.04.039

[52] R. Bhargava, P. K. Sharma, A. K. Chawla, S. Kumar, R. Chandra, A. C. Pandey and N. Kumar, "Variation in
Structural, Optical and Magnetic Properties of $\mathrm{Zn}_{1-\mathrm{x}} \mathrm{Cr}_{\mathrm{X}} \mathrm{O}$ $(\mathrm{x}=0.0,0.10,0.15$, and 0.20) Nanoparticles: Role of Dopant Concentration on Non-Saturation of Magnetization," Materials Chemistry and Physics, Vol. 125, No. 3, 2011, pp. 664-671.

doi:10.1016/j.matchemphys.2010.09.075

[53] M. Bouloudenine, N. Viart, S. Colis and A. Dinia, "Bulk $\mathrm{Zn}_{1-\mathrm{X}} \mathrm{Co}_{\mathrm{X}} \mathrm{O}$ Magnetic Semiconductors Prepared by Hydrothermal Technique," Chemical Physics Letters, Vol. 397, No. 1-3, 2004, pp. 73-76. doi:10.1016/j.cplett.2004.08.064

[54] K. J. Kim and Y. R. Park, "Spectroscopic Ellipsometry Study of Optical Transitions in $\mathrm{Zn}_{1-\mathrm{X}} \mathrm{Co}_{\mathrm{X}} \mathrm{O}$ Alloys," Applied Physics Letters, Vol. 81, No. 8, 2002, pp. 14201422. doi:10.1063/1.1501765

[55] A. J. Hays, A. Punnoose, R. Baldner, M. H. Engelhard, J. Peloquin and K. M. Reddy, "Relationship between the Structural and Magnetic Properties of Co-Doped $\mathrm{SnO}_{2}$ Nanoparticles," Physical Review B, Vol. 72, No. 7, 2005, pp. 075203-1-075203-7. doi:10.1103/PhysRevB.72.075203

[56] J. C. Pivin, G. Socol, I. Mihailescu, P. Berthet, F. Singh, M. K. Patel and L. Vincent, "Structure and Magnetic Properties of $\mathrm{ZnO}$ Films Doped with $\mathrm{Co}$, Ni or $\mathrm{Mn}$ Synthesized by Pulsed Laser Deposition under Low and High Oxygen Partial Pressures," Thin Solid Films, Vol. 517, No. 2, 2008, pp. 916-922. doi:10.1016/j.tsf.2008.08.125

[57] P. Sati, R. Hayn, R. Kuzian, S. Regnier, S. Schafer, A. Stepanov, C. Morhain, C. Deparis, M. Laugt, M. Goiran and Z. Golacki, "Magnetic Anisotropy of $\mathrm{Co}^{2+}$ as Signature of Intrinsic Ferromagnetism in ZnO:Co," Physical Review Letters, Vol. 96, No. 1, 2006, Article ID: 017203. doi:10.1103/PhysRevLett.96.017203

[58] O. D. Jayakumar, H. G. Salunke, R. M. Kadam, M. Mohapatra, G. Yaswant and S. K. Kulshreshtha, "Magnetism in $\mathrm{Mn}$-Doped $\mathrm{ZnO}$ Nanoparticles Prepared by a CoPrecipitation Method," Nanotechnology, Vol. 17, No. 5, 2006, pp. 1278-1285. doi:10.1088/0957-4484/17/5/020

[59] P. Sharma, A. Gupta, K. V. Rao, F. J. Owens, R. Sharma, R. Ahuja, J. M. O. Guillen, B. Johansson and G. A. Gehring, "Ferromagnetism above Room Temperature in Bulk and Transparent Thin Films of Mn-Doped ZnO," Natuew Materials, Vol. 2, 2003, pp. 673-677. doi:10.1038/nmat984

[60] N. S. Norberg, K. R. Kittilstved, J. E. Amonette, R. K. Kukkadapu, D. A. Schwartz and D. R. Gamelin. Journal of the American Chemical Society, Vol. 12, 2004, Article ID: 69387.

[61] K. Ueda, H. Tabata and T. Kawai, "Magnetic and Electric Properties of Transition-Metal-Doped ZnO Films," Applied Physics Letters, Vol. 79, No. 7, 2001, p. 988. doi:10.1063/1.1384478

[62] D. R. Lide, "CRC Handbook of Chemistry and Physics," 84th Edition, CRC Press, Boca Raton, 2003, pp. 12-125.

[63] K. Ariga, M. Li, G. J. Richards and J. P. Hill, "Nanoarchitectonics: A Conceptual Paradigm for Design and Synthesis of Dimension Controlled Functional Nanomaterials," Journal of Physical Chemistry, Vol. 11, No. 1, 
2011, pp. 1-13.

[64] N. H. Duc and T. Goto, "Handbook on the Physics and Chemistry of Rare Earthsvol," K. A. Gschneidner and L. Eyring, Eds., Elsevier, Amsterdam, 1999, p. 178.

[65] T. Goto, K. Fukamichi and H. Yamada. Physica B, Vol. 3, 2001, Article ID: 00167.

[66] E. P. Wohlfarth and P. Rhodes, "Collective Electron Metamagnetism," Philosophical Magazine, Vol. 7, No. 83, 1962 pp. 1817-1824. doi:10.1080/14786436208213848
[67] B. Pal and P. K. Giri, "Defect Mediated Magnetic Interaction and HighTc Ferromagnetism in Co Doped ZnO Nanoparticles," Journal of Nanoscience and Nanotechnology, Vol. 11, 2011, pp. 1-8. doi:10.1166/jnn.2011.4293

[68] V. A. Fonoberov, K. A. Alim, A. A. Balandin, F. Xiu and J. Liu, "Photoluminescence Investigation of the Carrier Recombination Processes in $\mathrm{ZnO}$ Quantum Dots and Nanocrystals," Physical Review B, Vol. 73, No. 16, 2006, Article ID: 165317. doi:10.1103/PhysRevB.73.165317 